\title{
Taxonomic notes on fossil beetles (Insecta: Coleoptera)
}

\section{Замечания по таксономии ископаемых зкуков (Insecta: Coleoptera)}

\author{
A.G. Kirejtshuk \\ А.Г. Кирейчук \\ Zoological Institute of the Russian Academy of Sciences, Universitetskaya Emb. 1, Saint Petersburg 199034, Russia. E-mail: agk@zin.ru, \\ kirejtshuk@gmail.com \\ Зоологический институт Российской академии наук, Университетская наб. 1, 199034, Санкт-Петербург, Россия.
}

KEY WORDS: new generic name, new synonymy, new taxonomic interpretations.

КЛЮЧЕВЫЕ СЛОВА: новое родовое название, новая синонимия, новые таксономические интерпретации.

ABSTRACT. The new name Lepichelus Kirejtshuk et Poinar, nom.n. is proposed for Lepiceroides Kirejtshuk et Poinar, 2013, non Schedl, 1957 (Lepiceridae). The synonymy Cervicatinius Tan et Ren, 2007 = Sinopeltis Yu, Leschen, Slipinski, Ren et Pang, 2012, syn.n. (Trogossitidae) and Forticatinius Tan et Ren, $2007=$ Paracretocateres Yu, Ślipiński, Leschen, Ren et Pang, 2015 syn.n. (Trogossitidae) were established. Some species of the family Eulichadidae are considered without generic attribution. Some corrections were made for the catalogue of Trogossitidae by Kolibác [2013], including the taxon Lithostomatini Kolibáč et Huang, 2008 is regarded without family and superfamily attribution (?Polyphaga, incertae sedis). For Smicrips cretacea Cai et Huang, 2016 (Smicripidae) was proposed a new genus Mesosmicrips Kirejtshuk, gen.n. (Mesosmicrips cretacea comb.n.).

РЕЗЮМЕ. Новое название Lepichelus Kirejtshuk et Poinar, nom.n. предложено для Lepiceroides Kirejtshuk et Poinar, 2013, non Schedl, 1957 (Lepiceridae). Установлены новая синонимия: Cervicatinius Tan et Ren, 2007 = Sinopeltis Yu, Leschen, Slipinski, Ren et Pang, 2012, syn.n. (Trogossitidae) и Forticatinius Tan et Ren, $2007=$ Paracretocateres Yu, Ślipiński, Leschen, Ren et Pang, 2015 syn.n. (Trogossitidae). Некоторые виды семейства Eulichadidae рассматриваются без родовой принадлежности. Предложены некоторые поправки для каталога Trogossitidae [Kolibáč, 2013], в том числе таксоны Lithostomatini Kolibáč et Huang, 2008 рассматривается без семейственной и надсемейственной принадлежности (?Polyphaga, incertae sedis). Для Smicrips cretacea Cai et Huang, 2016 (Smicripidae) предложен новый род Mesosmicrips Kirejtshuk, gen.n. (Mesosmicrips cretacea comb.n.).

Many published data on fossil beetles need reexamination and further corrections to nomenclature and taxonomic interpretations are required. Some of these corrections are made in the present work.

\section{Taxonomical notes}

1. The name Lepichelus Kirejtshuk et Poinar, nom.n. (combined from the generic names "Lepicerus" and "Haplochelus") is proposed for Lepiceroides Kirejtshuk et Poinar, 2013 (Myxophaga: Lepiceridae) [Kirejtshuk, Poinar, 2013], non Lepiceroides Schedl, 1957 (Polyphaga: Curculionoidea: Curculionidae) [type species: Lepiceroides aterrimus Schedl, 1957 (=Hypothenemus aterrimulus Wood, 1989, the latter name was proposed because the species name "aterrimus" was preoccupied by the senior Hypothenemus aterrimus Schedl, 1951 [Wood, 1989])].

2. The family Eulichadidae (Polyphaga, Byrrhoidea) includes of two subfamilies: Eulichadinae sensu str. and Lasiosyninae Kirejtshuk, Chang, Ren et Shih, 2010. The latter includes only two generic taxa Lasiosyne Tan, Ren et Shih 2007 (= Pappisyne Tan et Ren 2009) and Bupredactyla Kirejtshuk, Chang, Ren et Shih, 2010 and differs from the nominatine subfamily in "the slender and apparently more convex body, pronotum narrowed at base" and posterior angles projecting posteriorly, etc. [Kirejtshuk, Azar, 2013: 129]. According to this discrimination the taxon "Lasiosyne" laxa Yan, Wang et Zhang, 2014 with the very wide body and pronotum widest at base [Yan et al., 2014] should be remoted from the genus Lasiosyne and transferred into the nominative subfamily as "genus incertus" because the diagnostics of its generic taxa (Anacapitis Yan 2009; Crassisyne Yan, Wang et Zhang, 2014; Microsyne Yan, Wang et Zhang, 2014; Parelateriformius Yan et Wang, 2010) needs to be elaborated and the proposed key to genera of this group [Yan et al., 2013] shows very restricted possibilities to discriminate groups of available fossils species. Correspondingly, "Lasiosyne" punctata Yan, 2012 and "L." shartegiensis Yan, 2012 described after study only of some fragments of the posterior parts of their bodies [Yan, 2012] can be scarcely determined at both generic and subfamily level.

3. The synonymy Cervicatinius Tan et Ren, $2007=$ Sinopeltis Yu, Leschen, Ślipiński, Ren et Pang, 2012, 
syn.n. and Forticatinius Tan et Ren, 2007 = Paracretocateres Yu, Ślipiński, Leschen, Ren et Pang, 2015 syn.n. are clear because of a rather significant correspondence in the characters of both pairs of taxa, although the first taxon of each pair was erroneously described as a member of Catiniidae (Archostemata) [Tan, Ren, 2007], while the second was correctly assigned to Trogossitidae (Polyphaga: Cucujiformia: Cleroidea) [Yu et al., 2012, 2015. Kirejtshuk et al. [2010] first mentioned the correct attribution of both these genera and Nitidulina Martynov, 1926 to the suborder Polyphaga and superfamily Cleroidea, although Cai et al. [2015] regarded Forticatinius and Nitidulina as probable members of Artematopodidae (Polyphaga: Elateriformia).

4. In the catalogue by Kolibáč [2013] there are some deficiencies, some of which are rather important to be discussed. The author made some suppositions on fossils without re-examining the specimens. He put the tribe Lithostomatini Kolibáč et Huang, 2008 into the subfamily Trogossitinae sensu str. (Polyphaga: Trogossitidae) without providing reason for its subfamily or even family attribution. The type specimen of the type species of Lithostoma Martynov, 1926 (L. expansum Martynov, 1926) is missing now (it could be lost) and now it is possible to check the descriptor's characters only after study of similar specimens from the nearest locality in Karatau (Mikhalovka). Such a specimen was found in the Paleontological Institute of Russian Academy of Sciences in Moscow (PIN 2997/2167) which demonstrates the apparently convex body, very wide prosternal process and widely separate pro- and mesocoxae and, thus, this species is scarcely can be assigned not only to Trogossitidae but also to any cucujiformian group. In this catalogue there are included as "certain" Trogossitidae also other fossils remained unstudied by the author and some of them may be recognized as potential members of this family. Kolibáč [2006] approached Meligethiellinae Kirejtshuk et Ponomarenko, 1990 to the tribe Thymalini Léveillé, 1988, however later [Kolibáč, 2013] part of its members was interpreted as "Cucujoidea incertae sedis" with very disputable reasons: "(1) widely separated mesocoxae, especially in combination with (2) irregularly punctate elytra and (3) groove for prosternal process in mesosternum" [Kolibáč, 2013: 166]. Indeed taxonomy and systematic position of poorly described fossil species can be possible to clarify only after re-examination of the specimens described.

5. Cai et al. [2016] described the Mesozoic species of the genus Smicrips LeConte, 1878 (Polyphaga: Smicripidae) from Burmese amber, which, indeed, is very distinct from the Cenozoic members of this family and needs to be regarded separately from them, because, in contrast to species of the Smicrips, the Mesozoic specimen has the head longer and not subtriangular, with a clear median depression on the frons continuining posteriorly as a furrow reaching the vertex, eyes located at midlength of the head, scutellum subtrapezoid, and posterior edge of metaventrite arcuately excised. Besides, this specimen is only $1.28 \mathrm{~mm}$ long. Thus, taxonomic interpretation of this species should be regarded as a new genus as following: Mesosmicrips cretacea (Cai et Huang, 2016), comb.n. - Mesosmicrips Kirejtshuk, gen.n., type species Smicrips cretacea Cai et Huang, 2016.

ACKNOWLEDGEMENTS. The studies were partly carried out under the framework of the Russian state research project no. 01201351189, Presidium of the Russian Academy of Sciences "Problems of the origin of life and formation of the biosphere" and the Russian Foundation of Basic Research (grant 15-04-02971-a). The author greatly appreciate George Poinar (Oregon State University) for his generous comments to the manuscript.

\section{References}

Cai C.-Y., Lawrence J.F., Slipinski A., Huang D.-Y. 2015. Jurassic artematopodid beetles and their implications for the early evolution of Artematopodidae (Coleoptera)// Syst. Entomol. Vol.40. No.4. P.779-788

Cai C.Y., Huang D.Y. 2016. The first Mesozoic palmetto beetle (Coleoptera: Smicripidae) in Upper Cretaceous Burmese amber // Cretaceous Research. Vol.64. No.1. P.45-49.

Kirejtshuk A.G., Azar D. 2013. Current knowledge of Coleoptera (Insecta) from the Lower Cretaceous Lebanese amber and taxonomical notes for some Mesozoic groups // Terrestrial Arthropod Rev. Vol.6. No.1-2. P.103-134.

Kirejtshuk A.G., Poinar G. 2013. On the systematic position of the genera Lepiceroides gen.n. and Haplochelus with notes on the taxonomy and phylogeny of the Myxophaga (Coleoptera) // Azar D. et al. (eds.). Insect Evolution in an Amberiferous and Stone Alphabet. Brill. Leiden. P.55-69.

Kirejtshuk A.G., Ponomarenko A.G., Prokin A.A., Chang H., Nikolajev G.V., Ren D. 2010. Current knowledge on Mesozoic Coleoptera from Daohugou and Liaoning (North East China) // Acta Geol. Sinica. Vol.84. No.4. P.783-792.

Kolibáč J. 2006. A review of the Trogossitidae. Part 2: Larval morphology, phylogeny and taxonomy (Coleoptera, Cleroidea) // Entomologica Basiliensia et Collectionis Frey. Bd.28. S.105-153.

Kolibáč J. 2013. Trogossitidae: A review of the beetle family, with a catalogue and keys // ZooKeys. Vol.366. P.1-194.

Tan J., Ren D. 2007 Two exceptionally well-preserved catiniids (Coleoptera: Archostemata: Catiniidae) from the Late Mesozoic of Northeast China // Ann. Entomol. Soc. America. Vol.100. No.5. P.666-672.

Wood S.L. 1989. Nomenclatural changes and new species of Scolytidae (Coleoptera), Part IV// Great Basin Naturalist. Vol.49. No.2. P.166-185

Yan E.V. 2012. New beetle species of the genus Lasiosyne (Coleoptera, Lasiosynidae) from the Late Jurassic and Early Cretaceous of Russia and Mongolia // Paleontol. J. Vol.46. P.589-600.

Yan E.V., Wang B., Zhang H.C. 2013. First record of the beetle family Lasiosynidae (Insecta: Coleoptera) from the Lower Cretaceous of China // Cretaceous Res. Vol.40. No.1. P.43-50

Yan E.V., Wang B., Zhang H.C. 2014. A new lasiosynid beetle from the Middle Jurassic of China with remarks on the systematic position of Lasiosynidae // Comptes Rendus Palevol. Vol.13. No.1. P.1-8

Yu Y.L., Leschen R.A.B., Ślipiński S.A., Ren D., Pang H. 2012. The first fossil bark-gnawing beetle from the middle Jurassic of Inner Mongolia, China (Coleoptera, Trogossitidae) // Ann. Zool. (Warszawa). Vol.62. No.2. P.245-252.

Yu Y.L., Leschen R.A.B., Ślipiński S.A., Ren D., Pang H. 2015. New genera and species of bark-gnawing beetles (Coleoptera: Trogossitidae) from the Yixian Formation (Lower Cretaceous) of Western Liaoning, China // Cretaceous Res. Vol.53. No.1. P.8997. 